Vol. 2 | No. 4 | 2021 | Hal. 327-329

\title{
MENUMBUHKAN JIWA KEWIRAUSAHAAN PADA ANAK DENGAN PROGRAM LITTLE STAR ENTREPRENEUR
}

\author{
Tri Sugiarti Ramadhan*, Eka Farida \\ Fakultas Ekonomi dan Bisnis, Universitas Islam Malang \\ *korespondensi email: trisugiarti@unisma.ac.id
}

\begin{abstract}
ABSTRAK
Kewirausahaan merupakan kemampuan kreatif dan inovatif, jeli melihat peluang dan selalu terbuka untuk setiap masukan dan perubahan yang positif yang mampu membawa bisnis terus bertumbuh. Saat kondisi pandemic seperti ini penting nya mecari peluang untuk berwirausaha. Pembeljaran secara daring membuat remaja dan anak kecil memiliki waktu luang yang cukup untuk dapat dimanfaatkan mencari peluang berwurausaha. Pada kondisi seperti ini diharapkan remaja dapat memanfaatkan waktu dengan positif dan produktif. Kesiapan mental dan keterampilan perlu disiapkan sebelum seseorang memasuki dunia usaha. Berdasarkan hal tersebut, tujuan pengembangan kewirausahaan untuk remaja dan anak kecil sebagai berikut: 1) menumbuhkam jiwa kewirausahan, 2) mendorong dalam menggali potensi wirausaha melalui ide-ide kreatif, 3) manumbuhkan minat dalam berwirausaha. Kegiatan yang dilakukan meliputi pelatihan kewirausahaan, pelatihan pembuatan produk, edukasi kesadaran terhadap kewirausaha. Setelah kegiatan pengembangan kewirausahaan dilaksanakan, dilakukan evaluasi. Hasilnya menunjukkan 100\% peserta menyatakan mengalami peningkatan kesadaran akan kewirauasha dan skill setelah mengikuti kegiatan dan 90 \% menunjukkan perubahan sikap yaitu menjalankan usaha.
\end{abstract}

Kata Kunci: kewirausahaan, anak kecil, pelatihan kewirausahaan, kesadaran kewirausaha.

\section{PENDAHULUAN}

Dewasa ini seiring berkembangnya era digitalisasi anak anak mulai mengenal dan sudah banyak yang yang mengoperasikan gadget kadang kala gadget dapat membawa manfaat bagi anak namun disisi lain mereka juga dapat memilki sifat kecenderungan pada gadget. Seperti game online yang membuat mereka tidak bisa lepas oleh gadet. Melihat hal tersebut tentunya kia harus mampu mengendalikan bagaimana anak dapat bisa belajar maupun menyalurkan kreatif mereka terlepas dari asiknya bermain gadget.

Oleh karena itu, tujuan adanya Little Star Entrepreneur ini sendiri adalah untuk menyalurkan kreatifitas anak dan mengenal bagaimana dasar dasar kewirausahaan. Kemampuan wirausaha perlu dikenalkan sejak dini. Dengan mengenalkan permainan jual beli, secara tidak langsung, sudah mengenalkan jiwa entrepreneurship kepada anak.

Bagaimana usaha seorang pedagang yang akan menjual barangnya agar cepat laku. Lambat laun seiring peningkatan kognitif anak, maka kemampuan anak untuk berkreativitas dan memahami wirausaha akan semakin kuat.

Beberapa manfaat mengenalkan kewirausahaan pada anak adalah dapat mengasah imajinasi anak, anak dapat terlatih berbahasa dan akan memahami bagaimana etika yang 
seharusnya dilakukan ketika adanya transaksi, anak dapat mengenal fungsi uang dan mengenal nilai benda dan tentunya dapat memicu jiwa wirausaha pada anak itu sendiri.

\section{METODE}

Dalam mencapai tujuan yang diharapkan metode yang di gunakan adalah metode pendekatan serta partisipasi. Pogram KSM-Tematik ini di laksanakan di Dusun Durung Desa Jiyu, Kecamatan Kutorejo, Kabupaten Mojokerto. Prioritas yang telah di sepakati bersama dengan remaja dengan menggunakan aspek keterampilan, dan perilaku.

Berdasarkan aspek yang akan dikembangkan dalam kegiatan pelatihan kewirausahaan untuk remaja diatas, maka diperoleh evaluasi pelaksanaan, sebagai berikut Aspek keterampilan berkaitan dengan kemampuan dalam pembuatan produk yang akan dibuat, Aspek sikap berkaitan dengan kemampuan dalam menyelesaikan masalah dan kemampuan dalam komunikasi. Serta kesadaran dalam mencari peluang berwira usaha.

\section{HASIL DAN PEMBAHASAN}

Kegiatan little star and pernuer, meliputi:

1. Melakukan pendekan dengan memberikan beberapa game, selain dengan tujuan pendekatan juga meningkatkan fokus anak anak. Game yang diberikan pada waktu pendekatan meliputi: (1) Cerdas Cermat, (2) Simon Berkata, (3) Melanjutkan Lagu.

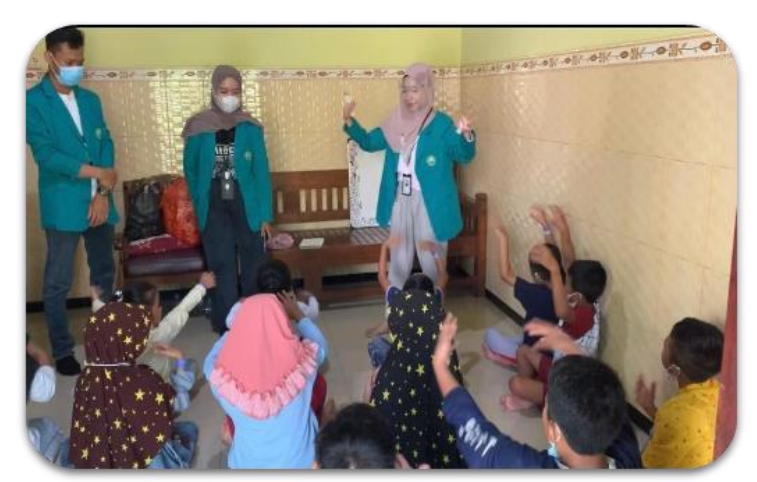

Gambar 1.

2. Pembagian masker.

3. Proses pengerjaan strap mask. Dimana anak-anak dibimbing untuk memasukan manik manik kedalam benang. Mereka dapat memilih model dan warna manik-manik sesuai dengan kreativitas mereka.

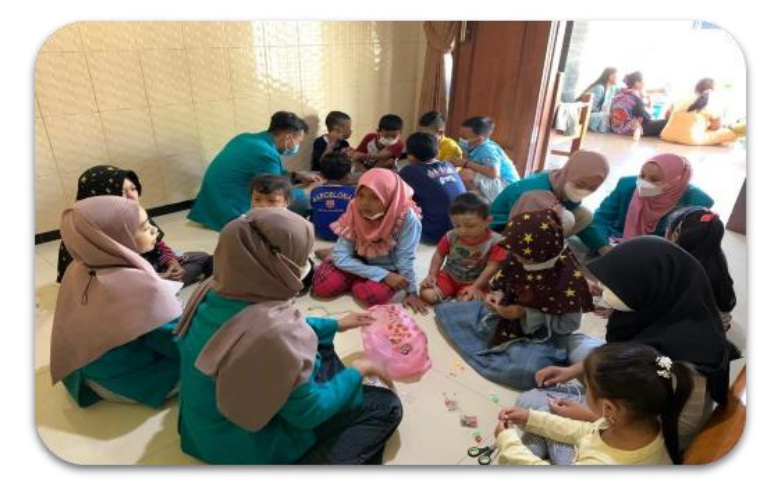

Gambar 2. 


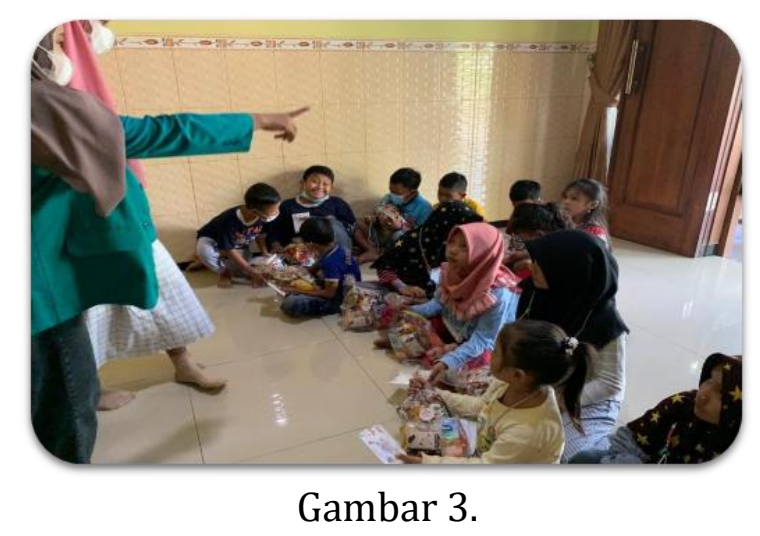

4. Pembekalan berupa ilmu mengenai kewirausahaan. Dimana dijelaskan mengenai modal awal, desain produk, pemasaran, laba atau keuntungan.

\section{KESIMPULAN}

Menumbuhkan jiwa kewirausahaan pada anak dengan program little star entrepreneur, meliputi Pendekatan melalui game. Kegiatan ini anak diberikan pemicu atau motivasi agar mereka bersemangat dan tentunya membuat mereka fokus akan apa yang mereka akan kerjakan. Pembagian masker. Kegiatan ini dimulai dengan memberikan masker agar dapat digunakan waktu kegiatan berlangsung maupun diluar kegiatan dan tentunya untuk menginterpretasikan hasil karya mereka berupa strap mask. Proses pengerjaan yang meliputi pembuatan strap mask dengan cara sederhana. Pembekalan ilmu kewirausahaan. Hal ini adalah inti dari program little star entrepreneur dimana mereka akan diberikan pengertian dasar mengenai apa itu kewirausahaan.

\section{DAFTAR RUJUKAN}

Nurhafizah. (2011). Keluarga sebagai Basis Pengembangan Nilai dalam Rangka Pembentukan Karakter Anak sejak Usia Dini. Sukabina Press: Padang

Rianto Nugroho. (2009). Entrepreneur Ciputra. Kompas Gramedia :Jakarta.

Syafitri, Nining. Faktor-faktor yang Mempengaruhi Belajar dan Pembelajaran. http://www.ningningocha.wordpress.com.21 November 2011

Sujiono, Yuliani Nurani. (2009). Konsep Dasar Pendidikan Anak Usia Dini. Jakarta: PT Macanan Jaya Cemerlang

Arifin, Z., \& Tamrin, T. (2019). Peningkatan Kompetensi Microcontroller Siswa SMK. Jurnal Inovasi Hasil Pengabdian Masyarakat (JIPEMAS), 2(1), 49-53. https://doi.org/10.33474/jipemas.v2i1.1772

https://www.hbics.sch.id/5-manfaat-pengenalan-wirausaha-sejak-dini-bagi-anak-anak/ 